\title{
DESAFIOS DA PÓS-GRADUAÇÃO DE ENFERMAGEM PARA A PRÓXIMA DÉCADA
}

\section{Alacoque Lorenzini Erdmann https://orcid.org/0000-0003-4845- 8515}

As políticas e estruturas dos Programas de Pós-graduação Stricto Sensu para a formação de mestres e doutores, no Brasil e em outros países, vêm sendo objeto de acompanhamento e apresenta perspectivas de mudanças bastante significativas, diante da realidade vivida nos últimos tempos, especialmente em decorrência da Pandemia de Covid-19.

Observa-se um importante avanço da ciência, da tecnologia e da inovação na promoção do desenvolvimento humano, político, econômico, social, cultural, ambiental e educacional, num momento de transição da era moderna para a contemporânea. Isso culmina com o desafio de acelerarmos nosso ritmo interativo, produtivo, participativo e colaborativo, rumo a novos modos de viver, ser e compreender a dinâmica do universo.

Nesse contexto, a Enfermagem trilha seu caminho em um turbilhão de demandas. Como era, não voltará a ser! Assim, quais serão as mudanças? Talvez impliquem em quebrar barreiras da profissão, especialmente as políticas e culturais, para poder mostrar sua força e seu grande potencial, já consolidado no domínio da atenção à saúde da sociedade, bem como, da formação de mestres e doutores enfermeiros, altamente qualificados e com perfis diferenciados, para melhor formar nossos novos enfermeiros e gerar ciência e tecnologias mais avançadas!

Na medida que se fortalece a formação avançada na Enfermagem, crescemos na qualificação do seu grande número de trabalhadores, para poder acompanhar os novos conhecimentos, saberes e práticas necessários para o melhor fazer da profissão.

Neste importante periódico científico do Conselho Federal de Enfermagem, encontramos possibilidades de desfrutar de leituras e contemplar esta nova tendência. É momento de pensarmos em estratégias e apoios para construirmos uma Nova Enfermagem... a Enfermagem do antes e do a partir de 2020, e que desejamos alcançar em 2025 e 2030!

Nossos Programas de Pós-Graduação Stricto Sensu serão mais integrados, diferenciados segundo as características culturais e vocacionais de cada região, centrados no fortalecimento e identidade da nossa disciplina de enfermagem, ciência e cuidados de enfermagem e saúde. Também serão mais integrados com as demais disciplinas e profissões da saúde e de outros campos de saberes, num exercício pleno de construção coletiva ou em redes de conhecimentos e tecnologias de modo inter e transdisciplinar, e interprofissional, para melhor incorporar a diversidade, o pluralismo, a complementaridade e os antagonismos do mundo contemporâneo.

Neste momento em que já contamos com enfermeiros mestres e doutores na prática profissional e na linha de frente de trabalho, nos sistemas ou serviços de saúde, podemos nos atentar para seus diferenciais e reconhecer os frutos destes niveis de formação, conhecimentos, domínios e atitudes, os quais são vitais para a valorização e o respeito pela nossa profissão.

Com o avanço da ciência e melhor compreensão do cuidado de enfermagem e saúde, em sua singularidade, despertamos para novos modos de organizar e gerenciar o trabalho da enfermagem e para a criação de novos espaços e ambientes de cuidados. As práticas dife- renciadas de cuidados à saúde das pessoas em outros contextos deste mundo, que cada dia mais possibilitam criar laços ou vínculos de sintonia e trocas de experiências, estão vindo a somar com outros segmentos, como aquele que já está à caminho, o de uma nova língua planetária, derivada das diversas línguas mais conhecidas de nosso planeta.

Para melhor compreender as pessoas, seu modo de viver e de ter saúde, de auxiliar na promoção dos cuidados essenciais para seu melhor viver e de garantir maior segurança de riscos e controles de sua vitalidade, os conhecimentos organizados em diversidades de núcleos se ampliam e diversificam, abrindo novos espaços para avançarmos e sermos melhores. Áreas de concentração, linhas de pesquisa ou de atuação, bases teóricas e filosóficas, éticas e políticas, evolução tecnológica da arte e técnica de cuidar alicerçado no saber científico, em congruência com o trabalho das demais profissões nos desafiam a planejar o que queremos e podemos ser, com estratégias que nos levem ao alcance de metas, na qualidade almejada.

O perfil na formação de nossos enfermeiros, mestres e doutores em Enfermagem vem tomando novas características de competências e domínios: tornando-se mais abrangente e global e, ao mesmo tempo, com maior profundidade e sustentação em novas evidências. E o mesmo vem acontecendo com o perfil dos nossos trabalhadores no campo da prática, suas competências e domínios. A educação permanente ou o aprender continuamente são parte das necessidades de capacitação para nos mantermos atualizados e capazes de fazer sempre o melhor cuidado.

A formação de doutores, cientistas da área, nos desafia a buscar novos domínios do aprender, do construir conhecimentos cada vez mais coletivos e colaborativos, e do aprofundar nossa capacidade de questionar a realidade, propondo novos caminhos ou subsídios. E a maior aproximação entre a formação do doutor acadêmico e do doutor profissional acontecerá na medida em que nossos laboratórios de estudos, pesquisas, tecnologia, inovação e gestão do conhecimento dominarem melhor a translação na geração de conhecimentos, dos básicos aos aplicados, com atores dominando as diversas etapas ou fases e tendo o raciocínio devido para aproximar, integrar e avançar nestas temáticas e objetos do nosso saber e do fazer o cuidado de enfermagem e saúde.

Conhecimentos aprofundados, práticas mais avançadas, articulação política e relação ética nos levarão a planejar estratégias desafiadoras, visionárias e empreendedoras para sustentar a nossa profissão social, científica e politicamente, no compromisso de fazermos o melhor para melhorar a saúde da sociedade e sermos coparticipes da construção de novas políticas públicas em todos os segmentos de produção e relação com o nosso cuidado, para um viver mais saudável.

Dez anos podem passar rápido, se não estivermos desafiados e organizados para aproveitarmos o momento e sonharmos um futuro bastante promissor e de destaque para a Enfermagem de nosso planeta. Potenciais é o que não nos falta! Vontade e determinação para grandes conquistas? Somos a profissão com o maior número de profissionais da área da saúde. O momento é agora, 2020!

IEnfermeira. Doutora em Filosofia da Enfermagem. Pesquisadora IA do CNPq. Professora Titular e Vice-Reitora da Universidade Federal de Santa Catarina, UFSC, SC, Brasil. Email: alacoque.erdmann@ufsc.br 